\title{
Nuclear Fusion and Reorganization in a Lactobacillus and a Streptococcus
}

\author{
By K. A. BISSET \\ Department of Bacteriology, University of Birmingham
}

SUMMARY: There is an apparent cycle of nuclear reorganization in Lactobacillus sp. Nuclear fusion occurs between the units of a multicellular bacillus. The organism then increases in length, the nucleoplasm being redistributed throughout the resulting filament, which by fragmentation returns to the bacillary condition. A very similar cycle is seen in Streptococcus faecalis.

Although the subject has not been very fully studied, a number of observations suggestive of nuclear reorganization in bacteria have been made. Stoughton (1932) and Braun \& Elrod (1946) produced strong evidence of conjugation in phytopathogens. Badian (1933) and Klieneberger-Nobel (1945) described a process of nuclear fusion as a preliminary to sporulation in species of Bacillus and Clostridium. Although sporulation was described as autogamous, it has been observed that bacilli of the types studied by Badian and KlienebergerNobel are usually multicellular (Robinow, 1945; Bisset, 1947), so that it is not unlikely that conjugation between the cells of multicellular bacilli was in fact observed.

The regular, if infrequent, occurrence in bacterial cultures of forms suggestive of such nuclear changes, led the author to search for a non-sporing species in which their occurrence was sufficiently frequent to enable them to be studied with advantage. These requirements were fulfilled by a number of strains of Lactobacillus sp., isolated in almost pure culture from a high proportion of samples from carious teeth. Observations were made upon 10 different strains which, although by no means identical, were all small, Gram-positive, acidophilic bacilli, of the general appearance of lactobacilli. In view of our limited knowledge of the taxonomy of this group, further identification was not attempted. Observations were also made upon a strain of Streptococcus faecalis in which similar forms were found.

\section{METHODS}

The bacteria were cultivated aerobically at $37^{\circ}$ upon nutrient agar containing $0.2 \%$ glucose, at $\mathrm{pH} 5$. Growth in $24 \mathrm{hr}$. under these conditions was slight; no growth at all was obtained at $\mathrm{pH} 7$. Cultures were examined at various ages from 4 to $72 \mathrm{hr}$., but those from 18 to $24 \mathrm{hr}$. old were found to be most productive of the types of cell which it was desired to examine.

Films were stained by Robinow's (1945) modification of the Feulgen technique. Robinow's tannic-acid-violet technique for the demonstration of cell walls was also employed. Wet preparations were always used. 


\section{OBSERVATIONS}

The lactobacilli were of Rough morphology, they formed 'medusa-head' colonies and possessed the multicellular structure and transverse septa typical of this state (Bisset, 1938, 1947) (Pl. 1, fig. 1). The chromatinic bodies were also arranged in the usual pattern of a Rough bacillus, each of the two or four cells of a bacillus containing a single body, probably an unresolved pair of chromosomes.

The bacteria in which apparent nuclear reorganization was observed were of two main types: (1) bacilli in which all the nuclear material appeared to have fused in the central region (Pl. 1, figs. 2-11); (2) filamentous organisms (Pl. 1, figs. 12-16). In the first type the size and appearance of the fused mass was variable. Usually there was some degree of central constriction, and sometimes the separate bodies composing it could be distinguished (Pl. 1, figs. 3, $5,10)$. Most frequently the dimensions were those of a four-celled bacillus, but some were little bigger than a two-celled bacillus. Comparison can readily be made in Pl. 1, fig. 2, where one of these forms and a typical four-celled bacillus are lying side by side. It should be noted that the apparent gap between the two halves of the latter represents a transverse septum, continuous with the cell wall (Pl. 1, fig. 1). The membranous septa which subdivide the two halves are better shown in the dividing bacillus on the right of $\mathrm{Pl}$. 1, fig. 3. In the second type the organisms varied in length from a little longer than the preceding type, to filaments, apparently unicellular, and as much as six or seven times as long. The smaller filaments contained one or more large, discrete masses of chromatinic material, and occasionally smaller, scattered masses (Pl. 1, figs. 12-15). In some of the larger filaments the chromatinic material was more evenly distributed, and signs of fragmentation of the filament were observed (Pl. 1, fig. 16).

Similar observations were made upon a strain of Strep. faecalis (Pl. 1, figs. 17-22). In this case the original fusion nucleus appeared to consist of a longitudinal bar of chromatinic material (Pl. 1, figs. 17, 18). The other forms which were observed closely resembled those seen in the lacto-bacilli, except that the lanceolate form of the coccus was always discernible, and the filaments formed were seldom very long (Pl. 1, figs. 19-22).

\section{DISCUSSION}

It appears logical to assume that a long filament is most probably derived from a shorter one, and can become short only by fragmentation, or by rejection of a portion of its material. Shrinkage in length alone is unlikely. It is therefore probable that the bacilli which contain the central mass of chromatinic material are derived from a normal bacillus (Figs. 1, 2), and grow into short filaments in which the chromatinic material is partly redistributed (Figs. 3, 4). These are transformed into longer filaments, where redistribution is completed and which return, by fragmentation, to the original bacillary condition (Fig. 5). The process in the streptococcus (Figs. 6-10) appears to follow a very similar 
pattern, although it is not clear whether the fusion nucleus is derived from a single coccus or, by conjugation, from more than one. A similar process was tentatively suggested by Robinow (1944) in his descriptions of certain types of cell found in cultures of Escherichia coli and Proteus vulgaris. His figures appear to represent similar forms to those described in the present paper, and he refers

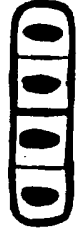

1

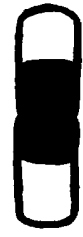

2

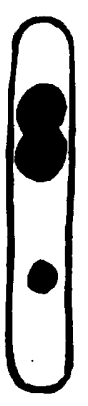

3

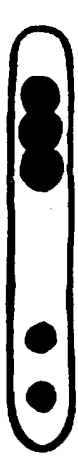

4

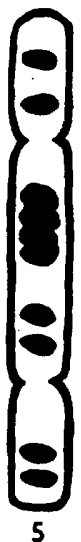

Figs. 1-5. Suggested interpretation of nuclear reorganization in Lactobacillus sp. (diagrammatic).

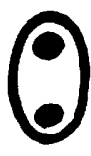

6

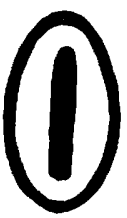

7

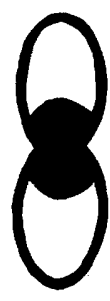

8

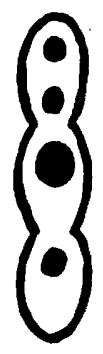

9

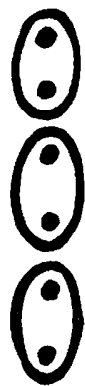

10

Figs. 6-10. Suggested interpretation of nuclear reorganization in Strep. faecalis (diagrammatic).

to the final step, the fragmentation of the filaments, in another publication (1947). The process also bears a resemblance to that described by KlienebergerNobel (1945) as a preliminary to sporulation, at least so far as the original nuclear fusion and redistribution is concerned. The reduction of chromatinic material which accompanies the actual process of sporulation has no obvious parallel in the present case, although it is not impossible that it may occur in the process of fragmentation, or by absorbtion of nuclear material in the cytoplasm in the manner described for Cytophaga (Krzemieniewska, 1930). This possibility is perhaps enhanced by the fact that the nuclear reorganization of Cytophaga takes place in a filamentous type of cell. It is also conceivable that the nuclear material in the filamentous form is not exclusively derived from the redistribution of the fusion nucleus, but that some portion arises 
Journal of General Microbiology, Vol. 2, No. 3
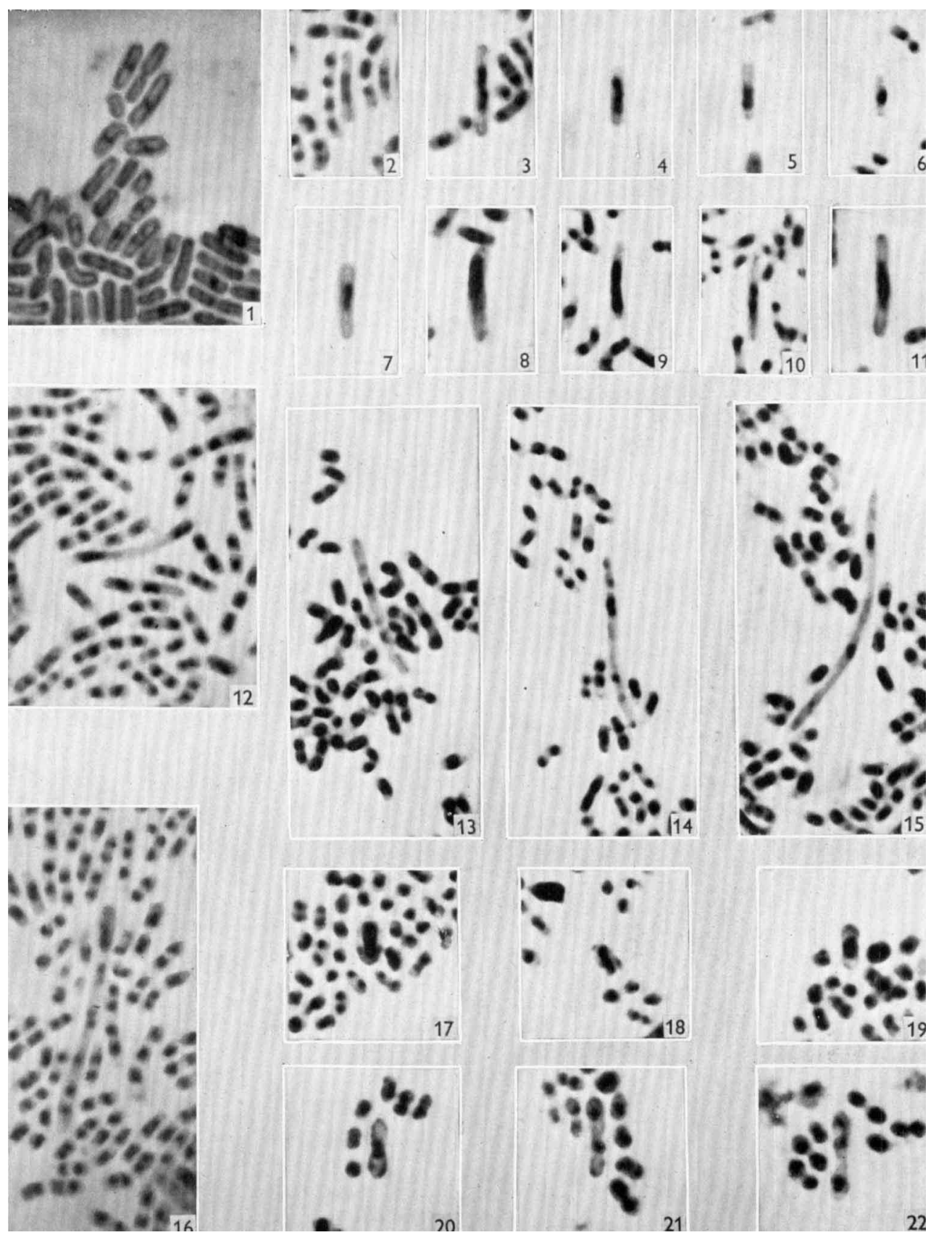

Figs, 1-22

K. A. Bisset-Nuclear fusion and reorganization in a lactobacillus. Plate 1 
de novo in the cytoplasm, or from structures analogous to a nucleolus. Studies by the author of these processes as they occur in Gram-negative, intestinal bacteria (Bisset, 1948) suggest that the chromosomes, which behave throughout as paired structures, divide once in the fusion nucleus and once during the redistribution; thus each chromosome of the three pairs which take part in the formation of the fusion nucleus gives rise eventually to a single bacillus containing two pairs of chromosomes. In the case of the Lactobacillus sp., where the bacillus contains four cells, each with a single pair of chromosomes, the details must be rather different, although, where they can be resolved the chromosomes appear to follow a similar general plan.

\section{REFERENCES}

Badian, J. (1933). Eine cytologische Untersuchung über das Chromatin und den Entwicklungzyklus der Bakterien. Arch. Mikrobiol. 4, 409.

Bisset, K. A. (1938). The structure of 'rough' and 'smooth' colonies. J. Path. Bact. 47, 223.

Bisser, K. A. (1947). The cytology of smooth and rough variation in bacteria. J. gen. Microbiol. 2, 83-87.

BIsset, K. A. (1948). Nuclear reorganization in non-sporing bacteria. J. Hyg., Camb. (in the Press).

Braun, A. C. \& Elrod, R. P. (1946). Stages in the life history of Phytomonas tumefaciens. J. Bact. 52, 695.

KIIENEBERger-Nobel, E. (1945). Changes in the nuclear structure of bacteria, particularly during spore formation. J. Hyg., Camb., 44, 99.

Krzemieniewska, H. (1930). Le cycle évolutif de Spirochaeta cytophaga. Acta. Soc. Bot. Polon. 7, 507.

Pringsheim, E. G. \& Robinow, C. F. (1947). Observations on two very large bacteria, Caryophanon latum Peshkoff and Lineola longa (nomen provisorium). J. gen. Microbiol. $1,267$.

Robinow, C. F. (1944). Cytological observations on Bact. coli, Proteus vulgaris and various aerobic spore-forming bacteria with special reference to the nuclear structures. J. Hyg., Camb., 43, 413.

Robinow, C. F. (1945). Addendum to: The Bacterial Cell by R. J. Dubos, Harvard University Press.

Stoughton, R. H. (1932). The morphology and cytology of Bacterium malvacearum E.F.S. Proc. Roy. Soc. B, 111, 46.

\section{EXPLANATION OF PLATE}

$$
\text { All } \times 3000
$$

Fig. 1. Lactobacillus sp., preparation of cell walls, showing septa. Tannic-acid-violet.

Figs. 2-11. Lactobacillus sp., forms showing fusion nuclei. Acid-Giemsa.

Figs. 12-16. Lactobacillus sp., filamentous forms showing redistribution of nuclear material. Acid-Giemsa.

Figs. 17-18. Streptococcus faecalis, forms showing fusion nuclei. Acid-Giemsa.

Figs. 19-22. Strep. faecalis, filamentous forms showing redistribution of nuclear material and fragmentation of filaments. Acid-Giemsa. 